\title{
Analysis of characteristics shown in self introduction letter and professor's recommendation letter
}

\author{
Sang Hyun Kim
}

Department of Microbiology, Kangwon National University School of Medicine, Chuncheon, Korea

\section{자기소개서와 교수추천서에 의한 일개 의과대학 응시자 특성 분석}

강원대학교 의학전문대학원 미생물학교실

\section{김상현}

Purpose: The purpose of this study was to investigate applicants' behavioral characteristics based on the evaluation of cognitive, affective and social domain shown in self introduction letter and professor's recommendation letter.

Methods: Self introduction letters and professor's recommendation letters of 109 applicants students who applied to medical school were collected. Frequency analysis and simple correlation were done in self introduction letter and professor's recommendation letter.

Results: Frequency analysis showed affective characteristics were most often mentioned in self introduction letter, and cognitive characteristics were most frequently described in professor's recommendation letter. There was a strong correlation between cognitive domains of self introduction letter and cognitive domain of professor's recommendation letter. There was a strong correlation between affective domain of self introduction letter and cognitive domain professor's recommendation letter.

Conclusion: It is very important to make full use of self introduction letter and professor's recommendation letter for selecting medical students. Through the frequency analysis and simple correlation, more specific guidelines need to be suggested in order to secure fairness and objectivity in the evaluation of self-introduction letter and professor's recommendation letter.

Key Words: Self introduction letter, Professor's recommendation letter

\section{서론}

자기소개서는 주로 진학과 취업을 목적으로 쓰이는 글로서 최근 다양화와 특성화를 추구하는 각 대학에서 모집단위 특성
에 적합한 학생들을 선발하거나 차별화된 인재를 선발하기 위 해 도입된 입학전형요소이다[1]. 자기소개서나 교수추천서는 학부모추천, 동료추천, 학생생활기록부, 면접 등의 여러 다면 정보에 속하며 국내 의학전문대학원(의전원) 입시에서 보편적 으로 사용되는 양식이다. 그 동안 활용범위가 제한적이었으나
Received: May 20, 2013 • Revised: June 27, 2013 • Accepted: July 23, 2013 Corresponding Author: Sang Hyun Kim

Department of Microbiology, Kangwon National University School of Medicine, 1 Gangwondaehak-gil, Chuncheon 200-701, Korea

Tel: +82.33.250.8863 Fax: +82.33.242.7571 email: sanghyun@kangwon.ac.kr
Korean J Med Educ 2013 Sep; 25(3): 189-199.

http://dx.doi.org/10.3946/kjme.2013.25.3.189

pISSN: 2005-727X eISSN: 2005-7288

(C) The Korean Society of Medical Education. All rights reserved. This is an open-access article distributed under the terms of the Creative Commons Attribution Non-Commercial License (http:// creativecommons.org/licenses/by-nc/3.0/), which permits unrestricted non-commercial use, distribution, and reproduction in any medium, provided the original work is properly cited. 
2007년도에 입학사정관제가 10 개 대학을 중심으로 시작되면 서 자기소개서의 중요성이 점차 커지게 되었다. 2013년 기준 으로 26 개 의전원 수시모집에서 25 개 의전원이 자기소개서 제 출을 요구하고 있으며 9 개 의전원이 교수추천서를 제출하도록 하고 있을 정도로 필수적인 전형요소로 인식되고 있다.

자기소개서는 자기보고서의 형태로 자아개념, 특기, 가치, 교내외에서의 활동과 성취 등에 대해 학생 자신이 설명하는 기록이며, 성적 등의 정량화된 도구로서 파악하기 힘든 학생의 논리력, 창의력 등의 특성을 나타내어 학생을 정성적으로 평가 하는 데 도움을 주는 양식이다[2]. 이러한 자기소개서에는 자 신의 능력에 대한 평가, 자신의 강점과 약점, 관심 분야, 지원 동기, 향후 학습 계획 등이 포함된다[2]. 또한 대학입시에서 사용되는 자기소개서에는 자신의 능력과 꿈 등과 관련하여 자 기 자신에게 문제를 제기하기도 하고, 그러한 문제를 해결하기 위해 어떠한 활동을 하였는지를 포함하기도 한다[3]. 그러므로 평가자 입장에서는 학생의 특성을 미리 파악하는 데 도움이 되고 구술 면접 시에 사전 질문거리를 만드는 데 실질적인 도 움을 준다[4]. 입학을 목적으로 쓰이는 자기소개서는 친교나 성찰을 목적으로 하는 글과는 다른 몇 가지 독특한 특징을 가 진다[5]. 첫째, 수필과 같이 주관적인 성격을 가진 글이 아니라 공적인 성격을 가진 글이므로 지나치게 친근하거나 독특한 표 현을 지양하고 객관적으로 작성되어야 한다[5]. 이러한 점에서 자기소개서는 James Britton의 글쓰기 분류에서 자기 표현적 글쓰기와 의사소통적 글쓰기의 중간단계에 위치한다고 볼 수 있다[6]. 둘째, 설득을 목적을 가진 의도적인 글이므로 평가자 의 의도를 염두에 두고 자신에 관한 긍정적인 정보를 전달할 수 있도록 작성되어야 한다[5]. 셋째, 분량이 정해진 글이다. 대부분의 의전원에서는 10 개 이내의 항목에 $400 \sim 1,000$ 자 이 내의 제한된 글자 수를 요구하고 있으므로 한정된 분량에 맞추 어 효과적으로 자신을 표현할 수 있도록 효율적인 단어를 선택 하여야 한다. 대학에서 자기소개서에 포함되기를 요구하는 내 용을 크게 4가지 영역으로 나누면 전공에 대한 열정(대학[학 과 지원 동기, 관심 분야, 학업 계획), 학과적성(지원자를 선발 해야하는 이유), 개인능력(자질, 가능성, 자기주도적 학습능 력), 개인인성(봉사, 도전의식, 대인관계)이다[5].

한편, 영재판별과정 중에서 일어나는 지능검사와 성취도검 사 등의 정량화된 검사 사이에 존재하는 선입견을 극복하기
위한 한 가지 방안으로 영재교육 대상자를 선발하는 데 있어 서 교사추천서가 널리 활용되고 있다[7]. 교수추천서는 지원 자의 특징을 다면적으로 기술하는 데 효과적이며 인지적 측 면을 강조하는 기존의 학점위주의 획일적 선발방법을 보완하 는 데 도움을 준다. 의전원 입시에서도 학부 성적과 영어 성적 등의 표준화된 도구의 한계를 보완하는 방안으로써 활용되는 교수추천서는 그 의의가 크다고 할 수 있다. 자기소개서에는 의전원에 지원하여 의사가 되고자 하는 학생의 행동특성이 나타나 있고, 교수추천서에는 교수가 오랜 기간 관찰해온 지 원자에 대한 행동특성이 나타나게 된다. 교수추천서는 교수 의 관점에서 쓴 내용이므로 주관적일 수 있지만 항목에 대한 정확한 기준이 제시되어 있고 객관적인 자세로 기술된다면 상당히 공식적일 수 있다[8]. 일반적으로 교수추천서에는 학 생의 인성, 전공 적합성, 발전 가능성, 창의성 요소가 포함되 지만 의전원 입학을 목적으로 쓰이는 교수추천서에는 의학도 로서의 기본 자질(성실성, 도덕성, 봉사정신), 발전 가능성(창 의성, 리더십, 도전정신, 대인관계), 의학 수행의 적합성(의학 수행의 열의, 준비도, 학습능력) 등이 포함된다.

2013년 기준으로 수시모집에서 26개 의전원 중 25개 의전 원이 자기소개서를 요구하고 있고 9 개 의전원이 교수추천서 제출을 요구할 정도로 의전원 입시에서 광범위하게 활용되는 만큼 현재 의전원 입학전형에 사용되는 자기소개서와 교수추 천서의 각 항목 및 모집단위에 대한 면밀한 검토를 통해 자기 소개서와 교수추천서가 의전원생 선발 과정에서 좀 더 공정 하고 객관적인 자료로 활용될 수 있는 방안을 모색해 보고자 하였다. 이번 연구에서는 의전원 입학생 선발에 사용되는 자 기소개서와 교수추천서에서 지원자와 교수가 기술하고 있는 내용을 인지적, 정의적, 사회적 행동특성으로 나누어 빈도분 석하였고, 자기소개서와 교사추천서 특성 간에는 어떠한 상 관관계가 존재하는지를 분석하였다.

\section{대상 및 방법}

\section{1. 연구 대상}

2013년도 강원대학교 의학전문대학원 입학생 선발 수시모 
집 응시자 109 명 중에서 일반전형 지원자 40명, 특별전형 지 원자 52명, 정시모집 응시자 중 M.D.Ph.D. 과정 지원자 17 명 (서류 미비 2명 제외)을 대상으로 하였다.

\section{2. 연구 방법}

수학과 과학 영재의 24가지 행동 특성 중에서 수학적, 과학 적 특성만을 표현하는 특성을 제외하고 일반적으로 지적으로 우수한 성인에게 적용 가능한 17 가지 특성을 이용하여 분석 하였다 $[9,10,11,12,13,14]$. 지원자와 교수가 언급하고 있는 내 용을 인지적 행동특성으로는 지적호기심, 문제해결능력, 창의 성, 자기주도적 학습능력, 의사소통능력 등 총 5항목, 정의적 행동특성으로는 의학적성, 자신감, 도전정신, 다재다능함, 완 벽주의, 자아개념, 내적동기, 적극성, 목표의식 등 총 9항목, 사회적 행동특성으로는 도덕성, 사회성, 리더십 등 총 3항목 으로 나누어 분석하였다(Table 1, Appendix 1, 2, 3).

\section{3. 자료 분석}

자기소개서와 교수추천서에 나타난 학생의 행동특성을 항목 별로 빈도분석하였다. 각 행동특성들의 빈도 차이의 유의성을 알아보기 위해 $\chi^{2}$ 검증을 실시하였고, 각 행동특성들의 상관 관계를 알아보기 위하여 Pearson의 단순적률상관계수를 이용 한 상관관계를 분석하였다. 모든 통계분석은 SPSS version 21.0 (IBM SPSS Inc., Chicago, USA)을 사용하였다.

\section{결과}

\section{1. 전체 지원지들의 자기소개서에서 니타난 행동특성}

앞서 정의한 행동특성이 내용상 드러났을 경우를 모두 합 하여 항목별 빈도수를 구하였다(Appendix 1, 2, 3). 총 109명

Table 1. Behavioral Characteristics Shown in Self Introduction Letter and Professor's Recommendation Letter

\begin{tabular}{ll}
\hline \multicolumn{1}{c}{ Domain } & \multicolumn{1}{c}{ Characteristics } \\
\hline Cognitive domain & Intellectual curiosity \\
& Problem solving ability \\
& Creativity \\
& Self-directed learning \\
& Communication skill \\
Affective domain & Attitude in medicine \\
& Confidence \\
& Challenging spirit \\
& Versatility \\
& Perfectionism \\
& Self-conception \\
& Inner motivation \\
& Initiative \\
& Awareness of purposes \\
& Morality \\
& Sociality \\
Social domain & Leadership \\
\hline
\end{tabular}

Fig. 1. Frequency Analysis of Behavioral Characteristics Shown in Self Introduction Letter and Professor's Recommendation Letter

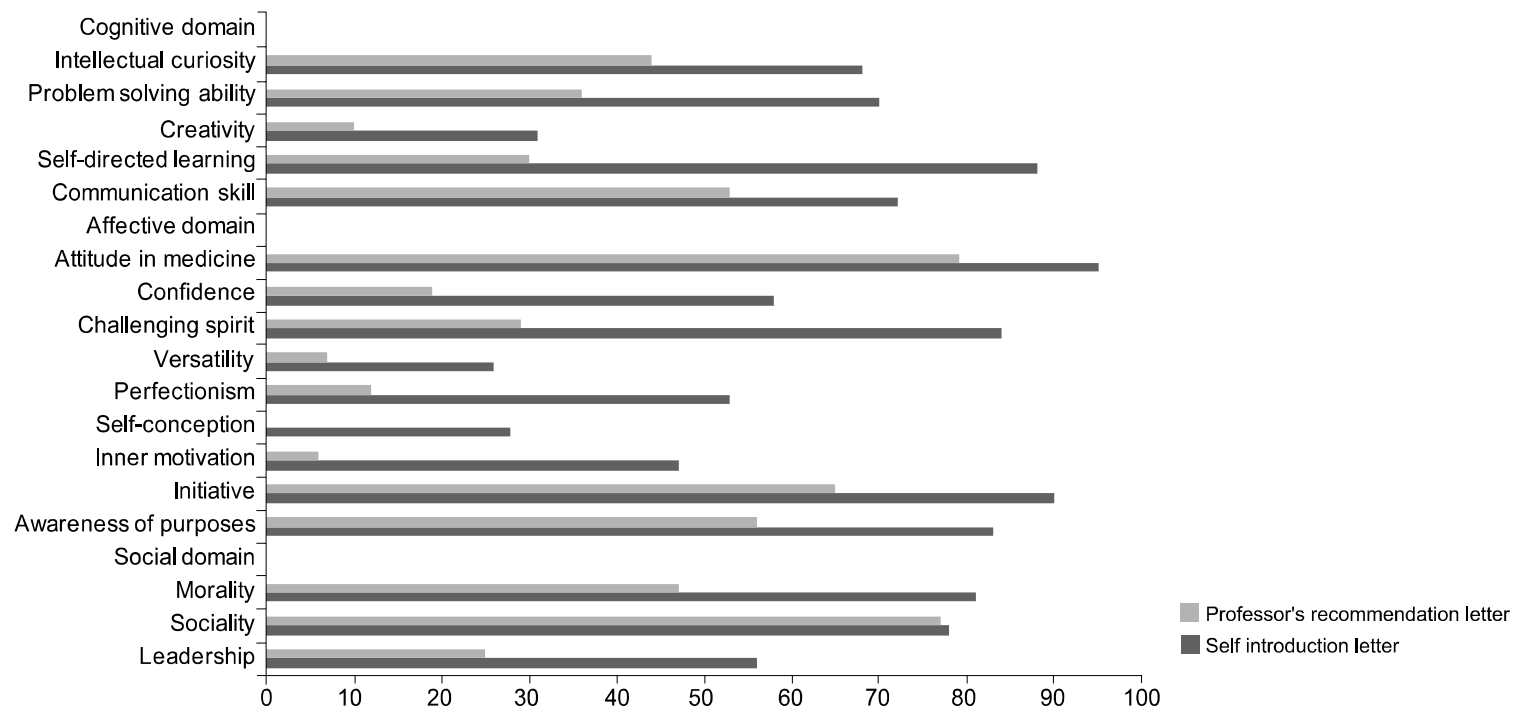


의 학생 중 95명의 학생이 의학적성을 가장 많이 기술하였으 며 적극성을 기술한 학생은 90명으로 그 다음이었다(Fig. 1). 반면에 다재다능함은 26 회, 자아개념은 28회로 가장 적게 기 술되어 있었다. 지원자들의 자기소개서에 나타난 인지적 특 성과 정의적 특성, 사회적 특성의 빈도수를 비교한 결과 정의 적 특성이 564회로 가장 많이 기술되어 있었다(Fig. 2). 자기 소개서에서 가장 많은 언급된 인지적 특성은 자기주도적 학 습능력과 의사소통능력, 문제해결능력 순이었다. 자기소개서 와 교수추천서에 기술된 행동특성의 빈도분포에서 차이가 있 는지를 알아보기 위해 $\chi^{2}$ 검증을 하였다. 인지적 행동특성인 지적호기심, 문제해결능력, 창의성, 자기주도적 학습능력, 의

Fig. 2. Frequency Analysis of Cognitive, Affective, and Social Domain Shown in Self Introduction Letter and Professor's Recommendation Letter

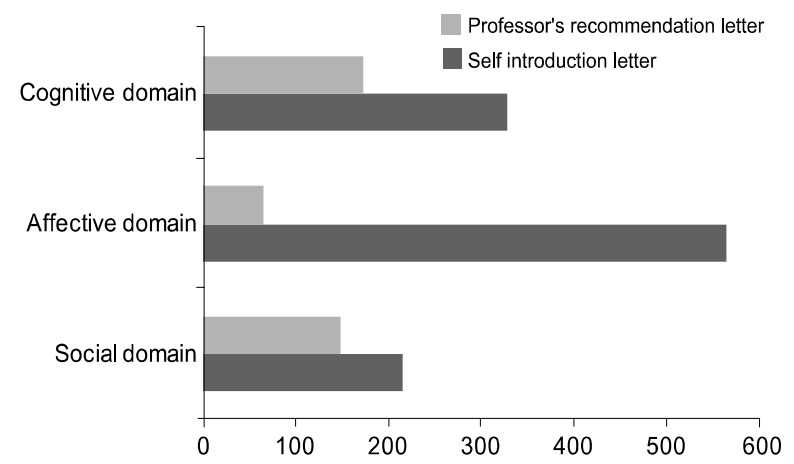

사소통능력 등 모든 인지적 특성 항목이 교수추천서보다 자 기소개서에서 많이 언급되었고 빈도수에서 의미 있는 차이를 보였다 $(\mathrm{p}<0.05)$. 정의적 특성에서 가장 많이 언급된 것은 의 학적성이었으며 그 다음은 적극성이었다. 의학적성은 모든 행동특성 중에서 가장 많이 언급된 특성이었다. 자기소개서 와 교수추천서에 언급된 학생의 행동특성의 빈도에서 차이가 있는지를 알아보기 위해 $\chi^{2}$ 검증을 한 결과 의학적성, 자신 감, 도전정신, 다재다능함, 완벽주의, 자아개념, 내적동기, 적 극성, 목표의식 등 모든 정의적 특성 항목이 자기소개서에서 보다 많이 언급되었고 빈도수에서 의미 있는 차이를 보였다 $(\mathrm{p}<0.05)$. 사회적 특성에서 가장 많이 언급된 것은 도덕성이 었다. $\chi^{2}$ 검증을 통해 도덕성, 사회성, 리더십 등 모든 사회적 특성 항목이 자기소개서에서 보다 많이 언급되었고 빈도수에 서 의미 있는 차이가 있음을 확인할 수 있었다 $(\mathrm{p}<0.05)$.

\section{2. 수시지원 학생과 M.D.Ph.D. 프로그램 지원학생 의 자기소개서에서 나타난 행동특성}

총 109명 학생 중 92명이 수시 지원 학생이었고 17명이 M.D.Ph.D. 프로그램 지원 학생이었다. 인지적 특성은 수시 지원 학생의 $57 \%$ 가 자기소개서에서 언급하였고 반면에 M.D.Ph.D. 프로그램 지원 학생은 $80 \%$ 가 언급하였다(Figs. $3,4)$. 정의적 특성은 수시 지원 학생의 $50 \%$ 가 자기소개서에 언급하였고 반면에 M.D.Ph.D. 프로그램 지원 학생은 $85 \%$ 가

Fig. 3. Percentage Analysis of Behavioral Characteristics Shown in Self Introduction Letter of Regular and M.D.Ph.D. Program Applicants

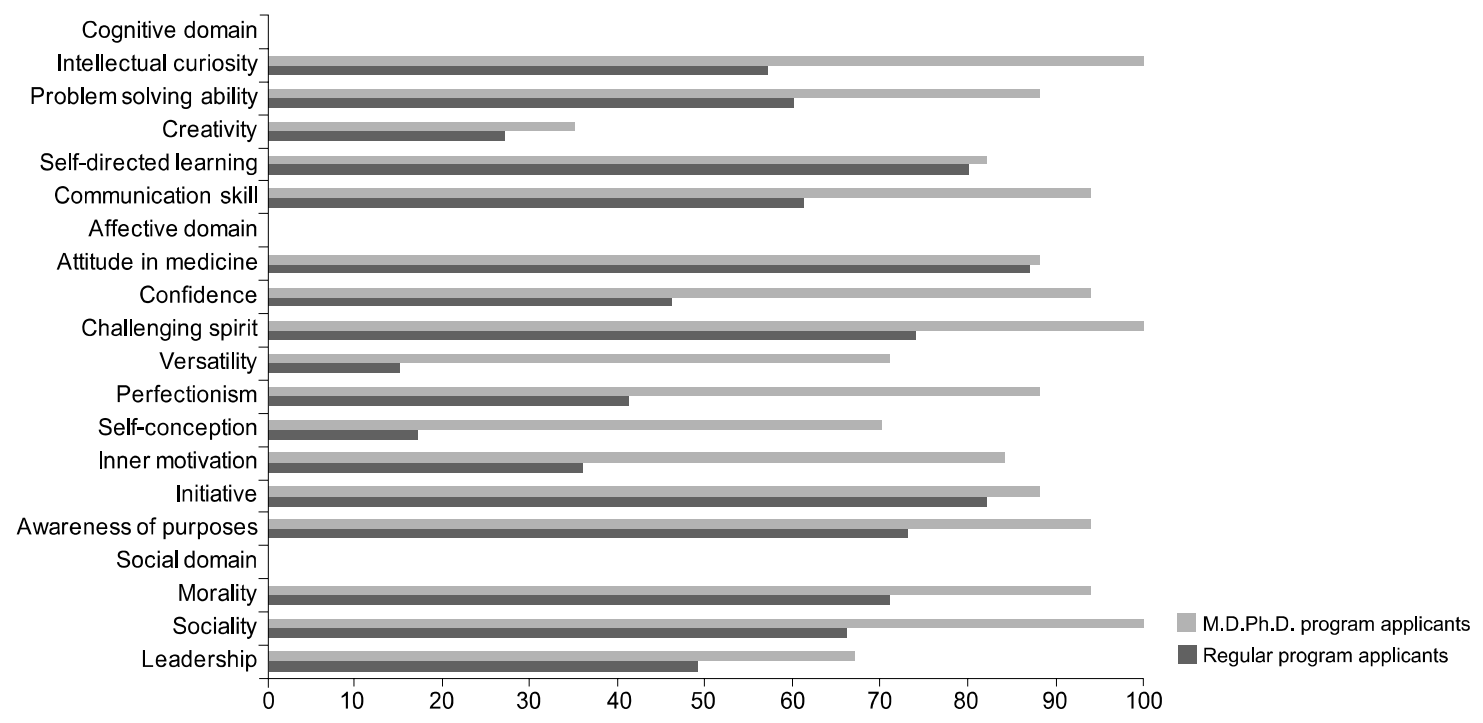


언급하였다. 사회적 특성은 수시 지원 학생의 $62 \%$ 에서 자기 소개서에 언급되어 있었고 반면에 M.D.Ph.D. 프로그램 지원 학생에서는 $88 \%$ 가 언급되어 있었다. 수시 지원 학생과 M.D.Ph.D. 프로그램 지원 학생의 자기소개서에 기술한 행동 특성의 빈도분포에서 차이가 있는지를 알아보기 위해 $\chi^{2}$ 검 증을 하였다. 지적호기심, 문제해결능력, 창의성, 인지적 특성 의 총합의 빈도수에서, 그리고 자신감, 도전정신, 다재다능함, 완벽주의, 자아개념, 내적동기, 정의적 특성의 총합의 빈도수 에서, 사회적 행동특성인 도덕성, 사회성, 사회적 특성의 총합 의 빈도수에서 M.D.Ph.D. 프로그램 지원 학생이 더욱 많이 언급하였고 의미 있는 차이가 있음을 확인하였다 $(\mathrm{p}<0.05)$.

Fig. 4. Percentage Analysis of Cognitive, Affective, and Social Domain Shown in Self Introduction Letter of Regular and M.D.Ph.D. Program Applicants

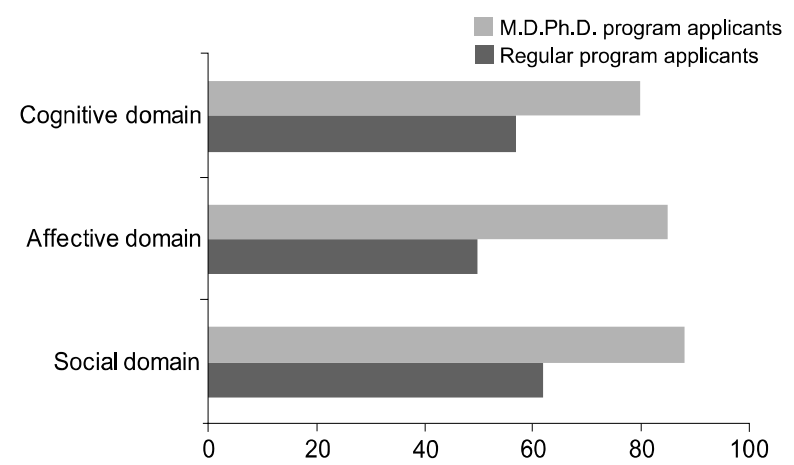

\section{3. 남학생과 여학생의 자기소개서에서 나타난 행동 특성}

총 109 명 학생 중 남학생 59 명, 여학생이 50 명이었다. 인지 적 특성은 남학생의 $61 \%$ 가 자기소개서에 언급하였고 여학생 은 $60 \%$ 가 언급하였다(Figs. 5, 6). 정의적 특성은 남학생의 $59 \%$ 가 자기소개서에 언급하였고 반면에 여학생은 $56 \%$ 가 언 급하였다. 사회적 특성은 남학생의 $62 \%$ 가 자기소개서에 언급 하였고 여학생은 $70 \%$ 가 언급하였다. 남학생은 자기소개서에 인지적 특성과 정의적 특성을 보다 많이 언급하였고 여학생 은 사회적 특성을 자기소개서에서 많이 언급하였다. 남학생

Fig. 6. Percentage Analysis of Cognitive, Affective, and Social Domain Shown in Self Introduction Letter of Female and Male Students

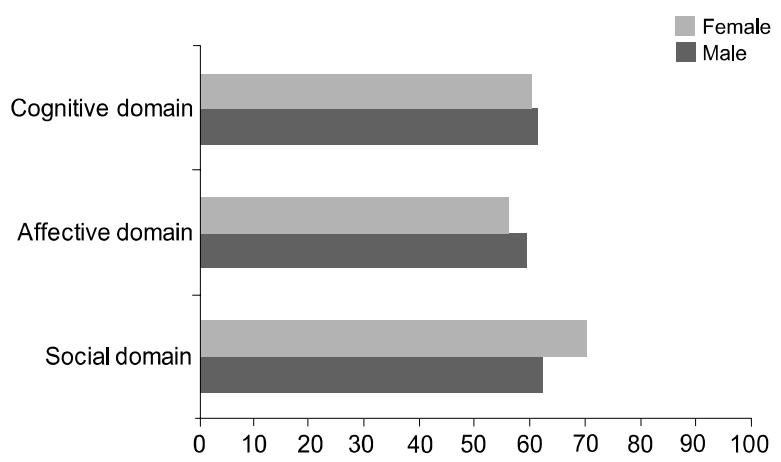

Fig. 5. Percentage Analysis of Behavioral Characteristics Shown in Self Introduction Letter of Female and Male Students

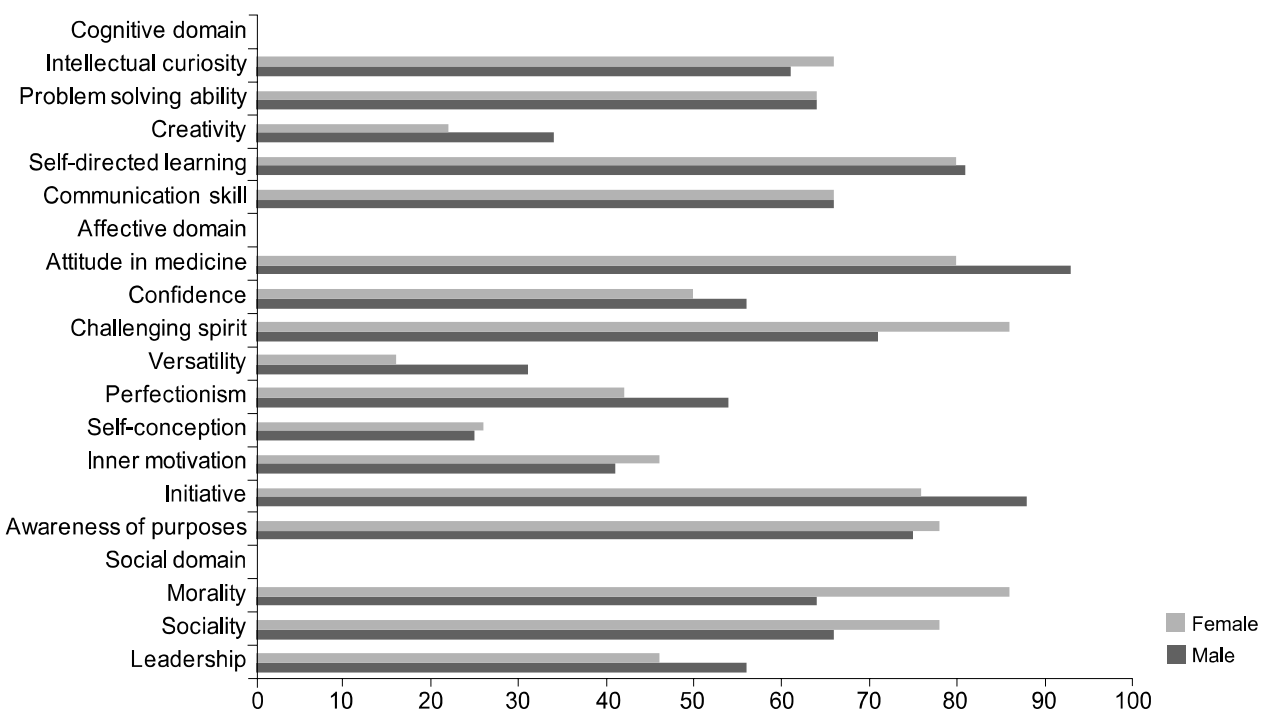


과 여학생의 자기소개서에서 기술한 행동특성의 빈도분포에 서 차이가 있는지를 알아보기 위해 $\chi^{2}$ 검증을 하였다. 남학 생은 정의적 특성인 의학적성, 다재다능함을 여학생보다 많 이 언급하였으며, 반면에 여학생은 도전정신과 도덕성을 남 학생보다 많이 언급하였고 의미 있는 차이가 있음을 확인하 였다 $(\mathrm{p}<0.05)$.

\section{4. 교수추천서에서 나타난 지원자의 행동특성}

교수추천서에서 교수가 지원자를 관찰해온 기간은 평균 3년 7 개월이었으며 범위는 6개월부터 11년 7개월까지 다양하였 다. 총 109 개의 교수추천서 중에서 의학적성이 79 회로 가장 많이 언급되었으며 사회성이 77회로 두 번째로 많이 언급되 어 있었다(Fig. 1). 의학적성은 자기소개서와 마찬가지로 교 수추천서에서 가장 많이 언급되어 있었다. 반면에 다재다능 함은 26 회, 자아개념은 28 회로 가장 적게 기술되어 있었다. 자기소개서에서 두 번째로 많이 언급된 특성은 90 회의 적극 성이었지만 교수추천서에서 두 번째로 많이 언급된 특성은 사회성이었다. 인지적 특성과 정의적 특성, 사회적 특성의 빈 도수를 모두 합한 총합은 자기소개서에서 1,108 회, 교수추천 서에서는 387회 나타났다. 교수추천서에 나타난 인지적 특성 과 정의적 특성, 사회적 특성의 빈도수를 비교한 결과 인지적 특성이 173회로 가장 많이 언급되어 있었다(Fig. 2). 두 번째 로는 자기소개서와는 상이하게 149회 언급된 사회적 특징이 었으며 마지막으로 65 회 언급된 정의적 특성이었다. 이는 자 기소개서와 가장 뚜렷한 차이를 보여주는 부분으로 자기소개 서에서 정의적 특성은 564 회로 가장 많이 언급되어 있지만 추
천서에서는 65 회로 가장 적게 언급되어 있었다. 교수추천서 에서 가장 많은 언급된 인지적 특성은 의사소통능력 53회, 지 적호기심 44회, 문제해결능력 36회 순이었다. 자기소개서와 마찬가지로 창의성에 대한 언급 빈도가 10회로 가장 적었다. 정의적 특성에서 가장 많이 언급된 것은 의학적성이며 그 다 음은 적극성이었다.

\section{5. 자기소개서와 교수추천서에 나타난 행동특성들 의 상관관계 분석}

자기소개서를 구성하는 하위 요소들의 상관관계를 알아보 기 위하여 분석하였다. 자기소개서 특성의 총합과 인지적 특 성 $(\mathrm{r}=0.776, \mathrm{p}<0.001)$, 정의적 특성 $(\mathrm{r}=0.887, \mathrm{p}<0.001)$, 그 리고 사회적 특성 $(\mathrm{r}=0.555, \mathrm{p}<0.001)$ 이 유의미한 정적 상관 관계를 나타내었다. 이는 지원자가 자기소개서 작성 시 인지 적 특성, 정의적 특성과 사회적 특성을 중요시하며 작성한다 고 할 수 있었다(Table 2). 교수추천서를 구성하는 하위 요소 들의 상관관계 분석 결과, 교수추천서 특성의 총합과 인지적 특성 $(\mathrm{r}=0.842, \mathrm{p}<0.001)$, 정의적 특성 $(\mathrm{r}=0.852, \mathrm{p}<0.0001)$, 그리고 사회적 특성 $(\mathrm{r}=0.618, \mathrm{p}<0.001)$ 이 유의미한 정적 상 관관계를 보여 주었다. 이는 교수들이 추천서를 작성할 때 학 생의 인지적 특성, 정의적 특성과 사회적 특성을 모두 고려하 며 작성한다고 해석할 수 있었다(Table 3). 자기소개서와 교 수추천서를 구성하는 하위 요소들과의 상관관계 분석 결과, 자기소개서의 인지적 특성과 교수추천서의 인지적 특성 $(\mathrm{r}=0.361, \mathrm{p}<0.0001)$ 이 유의미한 정적 상관관계를 나타내었 고, 자기소개서의 정의적 특성이 교수추천서의 인지적 특성

Table 2. Simple Correlation among Behavioral Characteristics Shown in Self Introduction Letter

\begin{tabular}{lllll}
\hline & & Cognitive domain & Affective domain & Social domain \\
\hline Cognitive domain & $\mathrm{r}$ & 1 & & \\
& $\mathrm{p}$-value & 0.508 & & \\
Affective domain & $\mathrm{r}$ & $0.000^{* *}$ & 1 & \\
& $\mathrm{p}$-value & 0.272 & 0.277 & 1 \\
Social domain & $\mathrm{r}$ & $0.004^{*}$ & $0.003^{*}$ & 0.555 \\
& $\mathrm{p}$-value & 0.776 & 0.887 & $0.000^{* *}$ \\
\hline
\end{tabular}

${ }^{*} p<0.01,{ }^{*} p<0.001$. 
Table 3. Simple Correlation among Behavioral Characteristics Shown in Professor's Recommendation Letter

\begin{tabular}{lllll}
\hline & & Cognitive domain & Affective domain & Social domain \\
\hline Cognitive domain & $\mathrm{r}$ & 1 & & \\
& $\mathrm{p}$-value & 0.534 & & \\
Affective domain & $\mathrm{r}$ & $0.000^{* *}$ & 1 & \\
& $\mathrm{p}$-value & 0.407 & 0.297 & 1 \\
Social domain & $\mathrm{r}$ & $0.000^{* *}$ & $0.002^{*}$ & 0.618 \\
& $\mathrm{p}$-value & 0.842 & 0.852 & $0.000^{* *}$ \\
\hline
\end{tabular}

${ }^{*} \mathrm{p}<0.01,{ }^{* *} \mathrm{p}<0.001$.

Table 4. Simple Correlation of Behavioral Characteristics between Self Introduction Letter and Professor's Recommendation Letter

\begin{tabular}{llccc}
\hline \multirow{2}{*}{ Professor's recommendation letter } & \multicolumn{3}{c}{ Self introduction letter } \\
\cline { 2 - 5 } & & Cognitive domain & Affective domain & Social domain \\
\hline \multirow{2}{*}{ Cognitive domain } & $\mathrm{r}$ & 0.361 & 0.377 & 0.183 \\
& $\mathrm{p}$-value & $0.000^{*}$ & $0.000^{*}$ & 0.056 \\
Affective domain & $\mathrm{r}$ & 0.239 & 0.410 & 0.221 \\
& $\mathrm{p}$-value & 0.012 & $0.000^{*}$ & 0.021 \\
Social domain & $\mathrm{r}$ & 0.162 & 0.159 & 0.111 \\
& $\mathrm{p}$-value & 0.093 & 0.098 & 0.251 \\
\hline
\end{tabular}

${ }^{*} \mathrm{p}<0.001$.

$(\mathrm{r}=0.377, \mathrm{p}<0.0001)$, 정의적 특성 $(\mathrm{r}=0.410, \mathrm{p}<0.0001)$ 과 유 의미한 정적 상관관계를 나타내었다(Table 4).

\section{고찰}

자기소개서와 교수추천서의 내용 분석을 통하여 의전원에 입학하려는 학생들이 자기 자신에 대해 기술한 행동특성과 학생을 곁에서 오랜 기간(평균 3년 7개월) 관찰해 온 교수가 객관적 입장에서 기술한 예비의료인의 행동특성을 확인하였 다. 개인의 풍부한 발달은 인지적 영역과 사회정의적 영역 간 의 상호작용을 통해서 이룰 수 있다고 한다[15]. 한편 영재의 경우 일찍부터 가치, 공정함, 정의감을 발달시키고 구체화시 키면서 내면화시킨다고 하였고 다른 사람의 권리와 감정을 쉽게 이해할 수 있다고 한다[2]. 의전원 지원자를 영재의 기준 에서 보았을 때 인지적, 정의적, 사회적 영역의 상호작용 속에 서 의사로서의 소양을 이룰 수 있으므로 인지적, 정의적, 사회
적 특성을 행동특성의 분석기준으로 사용하였다.

자기소개서와 교수추천서 모두에서 의학적성이 가장 많이 언급되었다. 교수와 학생은 공통적으로 의학적성을 중요시하 며 기술하고 있다는 것을 알 수 있었다. 의전원에 지원한 학생 은 자기소개서에서 지원하려는 학과의 특성이 자신들에게 적 합함을 우선적으로 강조한다는 것을 알 수 있었고, 교수는 의 사라는 직업적 특성에 지원자가 적합함을 추천서에서 우선적 으로 강조한다는 것을 알 수 있었다. 교수추천서의 사회적 특 성에서 가장 많이 언급된 것은 사회성으로 교수의 입장에서 는 사회에 잘 적응하고 대인관계가 원만한 것을 중요시한다 는 것을 알 수 있었다. 자아개념은 교수추천서에서는 언급되 어있지 않았고 자기소개서에서만 확인할 수 있었는데 이는 자기 자신에 대한 의식이 자기소개서에서만 나타나기 때문인 것으로 생각되었다. 학생은 자신의 내면적 특성을 가장 잘 보 여주는 정의적 특성을 자기소개서에서 가장 많이 언급하는 반면에 이를 확인하기 힘든 교수는 외면적 관찰이 용이한 학 생의 인지적 특성과 사회적 특성을 추천서에 많이 언급하고 
Sang Hyun Kim: Analysis of characteristics in self introduction letter and professor's recommendation letter

있음을 알 수 있었다. 학생 스스로가 창의성이 있음을 판단하 는 것은 다소 어려울 수가 있지만 창의성에 대한 언급 빈도는 31 회로 가장 적었는데 무의식, 직관적, 통찰적인 면과 관련된 창의성이 의전원에 지원하려는 학생에게서 부족할 가능성이 있다는 것을 알 수 있었다. 지적호기심, 문제해결능력, 창의 성, 자기주도적 학습능력, 의사소통능력 등 모든 인지적 특성 이 교수추천서에서보다 자기소개서에서 더 많이 언급되었고 빈도수에서 의미 있는 차이를 보여주었다 $(\mathrm{p}<0.05)$. 또한 수 시 지원 학생과 M.D.Ph.D. 프로그램 지원 학생의 자기소개 서에 기술된 행동특성의 빈도분포는 인지적 특성, 정의적 특 성, 사회적 행동특성에서 M.D.Ph.D. 프로그램 지원 학생이 의미 있게 많이 언급하였다 $(\mathrm{p}<0.05)$. 남학생은 정의적 특성 인 의학적성, 다재다능함을 여학생보다 많이 언급하였으며 반면에 여학생은 도전정신과 도덕성을 남학생보다 많이 언급 하여 남녀 학생 사이에 자기소개서를 기술하는 데 있어서 의 미 있는 차이가 있음을 확인하였다 $(\mathrm{p}<0.05)$.

지원자는 자신이 직접 기술한 자기소개서에 교수가 쓴 추 천서에서 보다 자신의 특성에 대해 약 3 배 더 많은 내용을 기 술하고 있음을 알 수 있었다. 학생은 자신의 소개서를 쓸 때 본인의 특성을 가장 잘 표현하려고 노력하고 있음을 알 수가 있었고 반면에 교수는 한 명의 학생만 추천하는 것이 아니라 여러 명의 학생들의 추천서를 써야하기도 하고 그 학생에 대 한 정확한 관찰과 이해가 부족한 가운데 추천서를 쓰기 때문 에 여러 행동특성의 기술도 많이 빈약해진다고 할 수 있었다. 또한 교수추천서에서는 인지적 특성이 가장 많이 언급되어 있으므로 교수들은 지원자의 특성을 파악할 때 인지적 특성 을 주로 관찰하고 추천서에 기술한다는 것을 알 수 있었다. 이 를 통해 평소에 학생면담과 생활지도를 할 때 교수들이 학생 들의 정의적 특성과 사회적 특성을 균형 있게 파악할 수 있도 록 체계적인 교수법이 의전원 차원에서 필요함을 제시해 주 었다. 교수는 학생의 학업에 대한 열정과 학습능력, 원만한 대 인관계, 의사소통능력을 추천서에서 많이 강조하는 경향이 있다는 것을 알 수 있었다. 자기소개서를 구성하는 하위 요소 들과의 상관관계를 분석한 결과 자기소개서에 인지적 특성이 서술되어 있는 학생일수록 교수추천서에서는 인지적 특성이 강조되고 있다고 해석할 수 있었고 자기소개서에 정의적 특 성이 서술되어 있는 학생일수록 교수추천서에서는 인지적 특
성과 정의적 특성이 강조되어 언급되어 있다고 해석할 수 있 었다(Table 3).

자기소개서와 교수추천서는 글 내용에 대한 신뢰도의 의문, 글쓰기의 기교가 실제 평가에 반영될 가능성이 높다는 점, 평 가자 간에 일관성 있는 채점이 어렵다는 점 등으로 인해 입학 전형에서 중요성이 간과되기 쉬운 면이 있다[12]. 그러나 대 학 학점과 영어 성적 등의 정량화된 자료만으로는 평가하기 어려운 학생의 다양한 정보를 수집 활용할 수 있는 자기소개 서와 교수추천서는 매우 귀중한 자료임이 분명하다. 자기소 개서의 내용과 양식은 각 대학별로 대학의 교육이념에 부합 하는 인재를 선발할 수 있도록 대학특성에 맞게 변경되어 사 용되기도 하지만, 지원자의 잠재능력을 다면적으로 평가하여 대학의 특성에 맞는 학생을 선발할 수 있도록 대학당국은 사 전에 자기소개서 작성에 관한 구체적이고 일관된 기준을 제 시하는 것이 좋겠다[3].

한편, 관찰 추천 영재 선발 시 사용되는 다면정보들을 활용 할 때는 여러 원칙들이 제시되고 있는데 이 중에서 총체적인 관점의 원리, 맥락성의 원리, 실증가능성의 원리, 개별성의 원 리, 집단 숙의의 원리 등은 의전원생을 선발할 때에 사용되는 자기소개서와 교수추천서에도 적용이 가능하다[16]. 총체적 인 관점의 원리란 가능한 한 여러 가지 평가정보를 수집하여 평가 정보 간의 교차 점검을 통해 종합적인 질적 판단을 하는 것이다. 인지적, 정의적 측면을 포함하여 체험 기록이나 추천 내용 등을 포괄적으로 고려하여 평가 교수 간의 집단 토론을 통해 점수로 정량화하지 않고 학생의 특성을 객관적으로 파 악할 수 있게 해 준다[16]. 맥락성의 원리란 지원자는 다양한 문화적, 경제적 영향을 받으며 성장하는데 학생의 현재의 모 습이 어떠한 영향을 받으면서 성취되었는지를 파악해 보는 것이다[16]. 실증가능성의 원리란 지원자는 자기소개서와 교 수추천서를 통해 자신을 능력을 과시하는 경향이 있으므로 실증적이고 객관적인 자료 검증을 통해서만 파악하는 것이다 [16]. 개별성의 원리란 학생의 고유한 인격, 잠재력 및 역량을 개별적으로 평가하고 가늠하는 것이다[16]. 집단 숙의의 원리 란 평가자인 교수개인의 주관적인 평가가 아니라 자기소개서 와 교수추천서에 나타난 사실에 대한 종합적인 이해를 바탕 으로 평가 교수들 간에 효과적이고 개방적인 토론을 통해 집 단적으로 판단하는 것이다[16]. 그러므로 이러한 원칙들을 활 
용하여 자기소개서와 교수추천서가 평가 된다면 의전원 입학 전형에 귀중한 자료들로 활용될 수 있을 것이다. 그리고 이와 더불어 학생의 잠재력을 공정하고 객관적으로 평가할 수 있 는 자기소개서나 교수추천서의 작성방법에 대한 연구도 지속 적으로 필요하다고 하겠다.

Acknowledgements: I appreciate the support according to this study by members of the Department of Microbiology, Kangwon National University School of Medicine, Chuncheon, Korea.

Funding: This study was supported by 2013 Research Grant from Kangwon National University (No. C1009821-01-01).

Conflicts of interest: None.

\section{REFERENCES}

1. Kim JR. A study on activity direction of a letter of self-introduction writing education: around assessment item and assessment element. Korean Lang Educ Res 2012; 44: 141-166.

2. Lee SD, Lee JK, Park CS. Introduction to gifted education. Seoul, Korea: Hakjisa; 2009.

3. Joe HH. Writing and evaluation of self introduction letter and statement of purpose. Seoul, Korea: Seoul National University Press; 2009.

4. Ha JA. The study on teaching elements for writing a self-introduction statement [master's thesis]. [Busan, Korea]: Pusan National University; 2010.

5. Han HS. A study in the aspects of self-introduction letter expressions. Mod Educ Korean Lang 2010; 85: 353-379.

6. Britton JN, ed. The development of writing abilities (1118). London, UK: Macmillan; 1975.

7. Kim MS, Lee HE, Lee HR, Bae JS, Park MG, Bonnie C,
Leehu Z. Study on the identification system for gifted programs in Korea. Seoul, Korea: Korean Educational Development Institute; 2009.

8. Sur HA, Kim YM, Jung YS. Observed and recommended method for gifted student for information science education. Busan, Korea: Busan Metropolitan City Office of Education; 2010.

9. Choi YJ. A comparison of leadership skills and social maturity between gifted and average elementary school students [master's thesis]. [Busan, Korea]: Pusan National University; 2009.

10. Karnes FA, Bean SM. Developing leadership in gifted youth. Reston, USA: ERIC Clearinghouse on Handicapped and Gifted Children; 1985.

11. Kim JH. A study on the validity of the rating scale for the gifted children [master's thesis]. [Seoul, Korea]: Sookmyung Women's University; 1995.

12. Park HJ. Analysis of inter rater reliability of self introduction letter and teacher's recommendation letter used in identification of gifted students by class observations and nominations [master's thesis]. [Incheon, Korea]: Incheon National University; 2011.

13. Song SH. A study on the development of an instrument to measure the behavior characteristics of the mathematical gifted children. Sch Math 2000; 2: 427-457.

14. Yun YH, Park SI, Joe SH, Kim HW, Lee JH, Jin SU, Han KS. Primary education. Seoul, Korea: Kyoyookbook; 2003.

15. Williams FE. The cognitive affective interaction model for enriching gifted programs. In: Renzulli JS. Systems and models for developing programs for the gifted and talented. Mansfield, USA: Creative Learning Press; 1986.

16. Choi HS. Identification of gifted students using observation. Changwon, Korea: Gyeongsangnam-do Office of Education; 2010. 
Sang Hyun Kim: Analysis of characteristics in self introduction letter and professor's recommendation letter

Appendix 1. Examples of Cognitive Domain Shown in Self Introduction Letter and Professor's Recommendation Letter [12,13,14]

\begin{tabular}{ll}
\hline \multicolumn{1}{c}{ 행동 특성 } & \\
\hline 지적호기심 & 정보습득이 빠르고 호기심과 궁금함이 많음. \\
& (자기소개서) 지식을 흡수하는 속도가 빠르며 지적탐구에 있어 주도성을 가지고 있습니다. \\
& (교수추천서) 강의 관련 저서를 매번 찾아서 읽고 해당 교수님께 직접 찾아가는 등 새로운 지식을 배우려는 자세가 \\
& 돋보였습니다.
\end{tabular}

Appendix 2. Examples of Affective Domain Shown in Self Introduction Letter and Professor's Recommendation Letter [12,13,14]

\begin{tabular}{|c|c|}
\hline 행동 특성 & 사례 \\
\hline 의학적성 & $\begin{array}{l}\text { 의학적 관심을 가지며 인성 품성 등 타고난 자질이 있음. } \\
\text { (자기소개세) 의학과 관련된 과목을 수강하며 취약한 아이들에게 근본적으로 도움을 줄 수 있는 의학지식이 필수적이라는 것을 } \\
\text { 깨달았습니다. } \\
\text { (교수추천세) 따뜻한 인성은 환자를 다루는 의사가 되는 데 매우 중요한 자질이라고 생각됩니다. }\end{array}$ \\
\hline 자신감 & $\begin{array}{l}\text { 어떤 일이 주어졌을 때 자신 있게 해결함. } \\
\text { (자기소개세) 국토순례팀에서 솔선수범하며 제가 할 수 있는 일을 발견하며 자신감을 키워나갔습니다. } \\
\text { (교수추천세) 연구실에 온지 몇 달 되지 않았지만 항상 자신감을 가지고 발표를 하였습니다. }\end{array}$ \\
\hline 도전정신 & $\begin{array}{l}\text { 어려운 일에도 정면으로 맞서서 해결함. } \\
\text { (자기소개세) 어린 나이에 홀로서기를 통해 배운 도전 정신은 지금껏 여러 가지를 이루게 한 밑거름이었습니다. } \\
\text { (교수추천세) 동물실험을 통한 결과가 잘 나오지 않자 실망하지 않고 더 큰 규모의 실험을 더 꼼꼼하게 계획하였으며 } \cdots .\end{array}$ \\
\hline 다재다능함 & $\begin{array}{l}\text { 다방면으로 흥미가 많으며 열정이 넘침. } \\
\text { (자기소개세) 합창단에서 활동하며 정기 공연과 축제를 준비하였습니다. } \\
\text { (교수추천세) 영어로 탁월한 의사소통능력을 갖추어 네팔 봉사활동에 참가하였습니다. }\end{array}$ \\
\hline 완벽주의 & $\begin{array}{l}\text { 최선을 다하는 생활 태도를 가지고 있으며 성공에 대한 욕구가 강함. } \\
\text { (자기소개서) 끊임없이 발전하기 위해 GRE를 준비하였고 미국 } \bigcirc \bigcirc \text { 의대 박사과정에 예비지원을 할 수 있었습니다. } \\
\text { (교수추천세) 심지어 그들의 동선까지 고려한 그 세심한 계획서를 보고 저는 매우 놀랐습니다. }\end{array}$ \\
\hline 자아개념 & $\begin{array}{l}\text { 자신을 유능하고 가치 있다고 생각함. } \\
\text { (자기소개세) 익숙지 않은 분야도 도전해서 꾸준히 일하면 제 자신의 한계를 넓힐 수 있다는 것을 알게 되었습니다. } \\
\text { (교수추천세) 없음. }\end{array}$ \\
\hline 내적동기 & $\begin{array}{l}\text { 학문에 대한 동기가 뚜렷하고 스스로 만족을 위하여 공부함. } \\
\text { (자기소개세) 어렸을 때부터 영어를 배우는 일이 의학관련 공부만큼이나 즐거워서 미국에 유학을 결심하였습니다. } \\
\text { (교수추천세) 교과서에 적혀 있지 않은 사항에 대하여도 끊임없이 고민하며 문제를 해결하곤 하였습니다. }\end{array}$ \\
\hline 적극성 & $\begin{array}{l}\text { 어떤 일이 주어졌을 때 자발적으로 주도적으로 나섬. } \\
\text { (자기소개서) 프로젝트에 열중하고 과제가 완성될 때까지 남들보다 앞서서 지속적으로 노력하였습니다. } \\
\text { (교수추천서) 과제를 내주면 그것에 국한되지 않고 과제 이외의 것도 준비하는 노력도 보여주었습니다. }\end{array}$ \\
\hline 목표의식 & $\begin{array}{l}\text { 의사로서의 장래희망이 분명하고 그것을 이루기 위한 계획이 있음. } \\
\text { (자기소개세) 그 동안 공부한 기초생물학을 기반으로 의학을 실현하는 의과학자가 되고자 } \bigcirc \bigcirc \text { 병원에서 연구원으로 2년간 일했습니다. } \\
\text { (교수추천세) 침착하게 자신과 동료들의 마음을 추스르며 안정되게 목표를 향해 정진하는 모습을 보였습니다. }\end{array}$ \\
\hline
\end{tabular}


김상현 : 자기소개서와 교수추천서에 나타난 응시자의 특성 분석

Appendix 3. Examples of Social Domain Shown in Self Introduction Letter and Professor's Recommendation Letter [12,13,14]

\begin{tabular}{|c|c|}
\hline 행동 특성 & 사례 \\
\hline 도덕성 & $\begin{array}{l}\text { 배려하고 나누고 봉사하는 태도를 가짐. } \\
\text { (자기소개세) 아침마다 수업에 가기 위해 보행을 도와주는 이동도우미 역할을 대학 생활 내내 했습니다. } \\
\text { (교수추천세) 바쁜 학부과정 중에도 자발적으로 치매노인을 도와드리는 봉사활동을 정기적으로 해왔습니다. }\end{array}$ \\
\hline 사회성 & $\begin{array}{l}\text { 사회에 잘 적응하고 대인관계가 원만함. } \\
\text { (자기소개세) 친구들의 감정을 이해하기 위해 노력하며 프로젝트를 책임 있게 수행했습니다. } \\
\text { (교수추천세) 공동실험을 하는 과정에서 원만하게 조정을 해가며 실험을 하는 모습을 보여주었다. }\end{array}$ \\
\hline 리더십 & $\begin{array}{l}\text { 조직을 이끌어가는 지도자로서 자질을 갖춤. } \\
\text { (자기소개세) 동아리 활동을 통해 친구들의 자신감을 북돋워주며 이끌어 갔습니다. } \\
\text { (교수추천세) 항상 일관된 모습으로 본인의 희망과 열정이 입에 구호로 그치는 것이 아니라 진심임을 보여 주었습니다. }\end{array}$ \\
\hline
\end{tabular}

